\title{
Safety and efficacy outcomes of a novel hysterosacropexy: A fertility sparing, uterine preserving pelvic organ prolapse surgery
}

\section{Original Article}

\author{
Ashraf Nassif Mahmoud Elmantwe, Mohamed Anwar Elnory
}

Department of Obstetrics and Gynecology, Faculty of Medicine, Benha University, Egypt

\begin{abstract}
Objective: To access the safety and efficacy outcomes of a new abdominal Hysterosacopexy with CESA (Cervicosacropexy) DynaMesh kit in treating advanced uterovaginal prolapse in young women aiming in uterine preservation pelvic organ prolapse (POP) surgery.

Patients and Methods: Prospective nonrandomized controlled clinical trial enrolled consecutive women attending the gynecology and obstetrics Department, Benha University Hospital for treatment of POP of stage II or greater on POP quantification (POPQ) system on the apical domain. Participants underwent abdominal hysterosacropexy utilizing CESA mesh kit of DynaMesh. POPQ staging, women symptoms, and quality of life were evaluated before and after surgery, as well as surgery-related morbidity.

Results: The current study enrolled 20 women, all women were followed up for a period of 18 months postoperatively. Significant post-surgical anatomical success was recorded across both POPQ anterior (point Aa, Ba) $(P \leq 0.0001$, $P \leq 0.0001)$, apical (point c, d) $(P \leq 0.0001, P \leq 0.0001)$ and Posterior (point Ap, Bp) $(P \leq 0.0001, P \leq 0.0001)$ domains. Significant post-surgical functional improvements were recorded across prolapse symptoms, (bulge symptoms, overactive bladder, stress urinary incontinence, bowel dysfunction, sexual dysfunction) $(P \leq 0.0001, P=0.0064, P=0.03$, $P=0.008, P \leq 0.0001)$ respectively. ICIQ-VS $(\mathrm{VS}-\mathrm{SS}-\mathrm{QOL})$ score $(P \leq 0.0001, P \leq 0.0001, P \leq 0.0001)$. ICIQ - UI - SF score $(P \leq 0.0001)$. No major complications occurred. No mesh erosions were reported.

Conclusion: Abdominal hysterosacropexy with CESA DynaMesh kit seems to be a safe and effective option for women with advanced uterovaginal prolapse aiming for uterine preserving POP surgery.
\end{abstract}

Key Words: Cervico-sacropexy(CESA), CESA DynaMesh, hysterosacropexy, polyvinylidene fluoride (PVDF), spinal anesthesia

Received: 4 June 2018, Accepted: 29 June 2018

Corresponding Author: Ashraf Nassif, Department of Obstetrics and Gynecology, Benha University, Benha, Egypt, Tel.: 010166667326, E-mail: Ashrafelmentawe2012@gmail.com

ISSN: 2090-7265, August 2018, Vol.8, No. 3

\section{INTRODUCTION}

Pelvic organ prolapse may occur in up to $50 \%$ of parous women $^{[1]}$. Prolapse involves anterior compartment triple more than posterior compartment and twice more than apical compartment. However POP is dynamic, and about two-thirds of women with POP have prolapse of more than one compartment ${ }^{[2]}$.

Classically, surgical correction of uterovaginal prolapse is included a hysterectomy, despite the fact that the uterus is believed to be a negative organ in pelvic organs prolapse pathogenesis ${ }^{[3]}$. Nowadays, women prefer uterine preservation for several reasons, including cultural beliefs, personal preferences, sexual identity, fertility preservation and fear of Hysterectomy sequels ${ }^{[3]}$.

There are various Hysteropexy techniques: vaginal Hysteropexy includes Manchester procedure, sacrospinous hysteropexy, vaginal mesh hysteropexy. Abdominal hysteropexy includes laparotomic or laparoscopic hysteropexy and uterosacral hysteropexy ${ }^{[3]}$.

Sacral Hysteropexy was effective as hysterectomy with sacral colpopexy in anatomical outcomes, However hysterectomy with sacral colpopexy was associated with five-time high in mesh exposure compared to sacral hysteropexy ${ }^{[3]}$.

Owning to bloody nature of the Manchester procedure, high recurrence and dyspareunia with sacrospinous hysteropexy, and warning of food and drug administration (FDA) about vaginal mesh safety, there is a change in practice patterns among urogynecologists with a decrease in vaginal mesh and increase in sacropexy ${ }^{[3,4]}$.

Abdominal sacropexy is considered to be the gold standard in POP surgery as it is associated with apical 
success rates of $93-99 \%$ along with low recurrence rates $^{[5]}$. However, new-onest bowel dysfunction, voiding problems, sexual dysfunction and mesh erosion were reported ${ }^{[1,6,7,8,12]}$.

Bilateral cervico-sacropexy (CESA) using a predesigned mesh kit was first described by Jager et al. for treating POP associated urge and mixed incontinence ${ }^{[9]}$, in which the uterosacral ligaments (USLs) were augmented by alloplastic mesh, that reattach the cervix (cervicosacropexy "CESA") or vaginal vault (vagino-Sacropexy "VASA") to the second sacral vertebra (S2) $)^{[9]}$.

Synthetic mesh [type I polypropylene (PP)] was proven to be better than biological mesh (cadaveric fascia Lata, procaine dermis) regarding reduced failure rates of sacropexy ${ }^{[10,12]}$. Sutures and meshes made from PVDF have been widely used in cardiac, ophthalmic, vascular, orthopedic and general surgery because of material's high biocompatibility and reduced bacterial adherence ${ }^{[11,12]}$.

In the current study, the DynaMesh CESA mesh system (FEG, tetitechnik, mbH, Aachen, Germany) was used (Fig. 1).

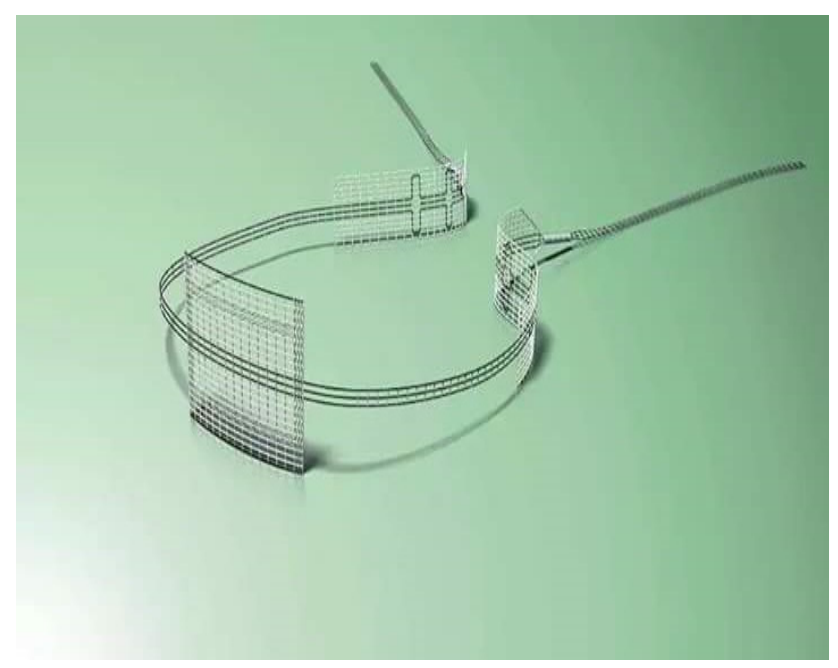

Fig. 1: DynaMesh CESA kit system (FEG textiltechnik mbH, Aachen, Germany) reproduced with written permission from the company

It is bulided of three small pieces of PP type I mesh: a central rectangular piece to be attached to the cervix and two peripheral pieces to be anchored to the ventral surface of the S2 on both sides of the rectum. This three pieces integrated with each other by suture bridges mesh, this minimizes the amount of synthetic material used. The volume of mesh used in CESA is about $10 \%$ of the volume of PP mesh used for traditional sacropexy. The CESA mesh is made of monofilament polyvinylidene fluoride (PVDF), and it is macroporous "pore size $6 \mathrm{~mm}$ ". The CESA mesh could be visualized by MRI as it was impregnated with iron $^{[9,16,17,18]}$.
The CESA mesh had high shape stability and defined elasticity which allows pelvic floor mobility, although the mesh retains its shape when exposed to stresses placed on the pelvic floor ${ }^{[9]}$. The CESA mesh is designed for cervicosacropexy and has to be anchored in place in the same way as described by Jager et al. ${ }^{[9]}$. This maintains standardization of the technique and allows for better interpretation of the effects of the procedures across different centers.

The aim of the present trial was to evaluate the safety and efficacy of bilateral uterosacral ligaments augmentation Hysterosacropexy using CESA mesh kit of DynaMesh in treating advanced uterovaginal prolapse in young women aiming in uterine preservation POP surgery.

\section{PATIENTS AND METHODS}

The present study is a prospective nonrandomized controlled clinical trial on twenty women with uterine prolapse ICS POP Q Stage II or greater who were interested in uterine preserving POP surgery without contraindication for uterine preservation as uterine pathology, cervical dysplasia, high risk for genital cancer and without contraindication for sacropexy as pelvic adhesion.

The present study was done over three years from October 2014 to December 2017 at Benha University Hospital. Ethical approval was taken from obstetrics and Gynecology Department of Benha University Hospital. Also, a consent was taken from all women enrolled in the study.

Preoperative assessment included a standardized history of prolapse symptoms (Vaginal lump or discomfort), urinary symptoms (Urgency, Frequency, Urge or Stress incontinence and voiding difficulty), bowel symptoms (fecal urgency, difficulty with defecation and constipation) and sexual dysfunction secondary to prolapse. Other relevant history items were observed as prior pelvic surgery especially for prolapse, risk factors for genital malignancy as family history of breast, endometrial and ovarian cancer.

Objective assessment of prolapse was performed in left lateral position during Valsalva maneuver using a Sims speculum. The ICS POPQ scale was used to quantify the degree and type of prolapse at all sites before and after the procedure ${ }^{[13]}$. Transvaginal ultrasound, outpatient endometrial sampling, and Pap smear were done to exclude any contraindication. Before surgery and at $6,12,18$-month postoperative women with the authors' help also to complete the ICIQ-VS(VS-SS-QOL)(14) and ICIQ-UI- SF(15) questionnaire.

The primary measure of the successful objective outcome was the absence of uterine descent postoperatively. Surgical cure of uterine descent was defined as point C, D 
of stage 0 , I on ICS POP-Q system. We also recorded the presence or absence of prolapse in any other compartment. The functional outcomes were assessed by improvement in prolapse symptoms, ICIQ-VS(VS-SS-QOL) score ${ }^{[14]}$ and ICIQ-UI-SF score ${ }^{[15]}$.

The abdominal new hysterosacropexy procedure was done under spinal anesthesia with sedation, or general anesthesia women were placed in modified lithotomy position. Pfannenstiel incision was done, the USLs were identified at the cervix by pulling the uterus up and forward. A rectangular tongue-like flap over the posterior aspect of the cervix was made. The peritoneum over S2 was incised vertically $2 \mathrm{~cm}$ long, on either side of the rectum. The central piece of the CESA mesh was sutured to the back of exposed cervix by four interrupted nonabsorbable (PP1) stitches at the mesh corners, and the fifth stitch was taken in mesh center (Fig. 2).



Fig. 2: the Central piece of CESA DynaMesh kit sutured to the back of the cervix and scissors pointed to uterosacral ligaments

A special tunneler or long curved artery forceps was then introduced from the sacral peritoneal window under the peritoneum a long the USL toward the cervix. The tape arm was fed through the eye of the tunneler or caught with the curved artery forceps and brought back to sacrum, the lateral two pieces of CESA was anchored to periosteum of S2 with two horizontal interrupted stitches of non absorbable (PP1) as in predesigned fashion by Jager et al., (Fig. 3).

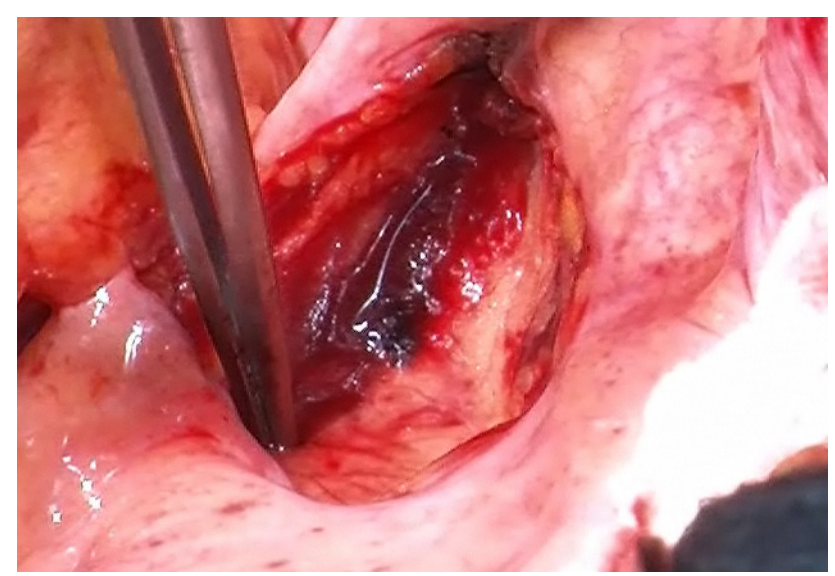

Fig. 3: The right lateral piece of CESA DynaMesh kit anchored to the second sacral vertebra
At the end, the peritoneum over the cervix (Fig. 4) and the sacrum were closed, so the CESA mesh was extraperitoneal.

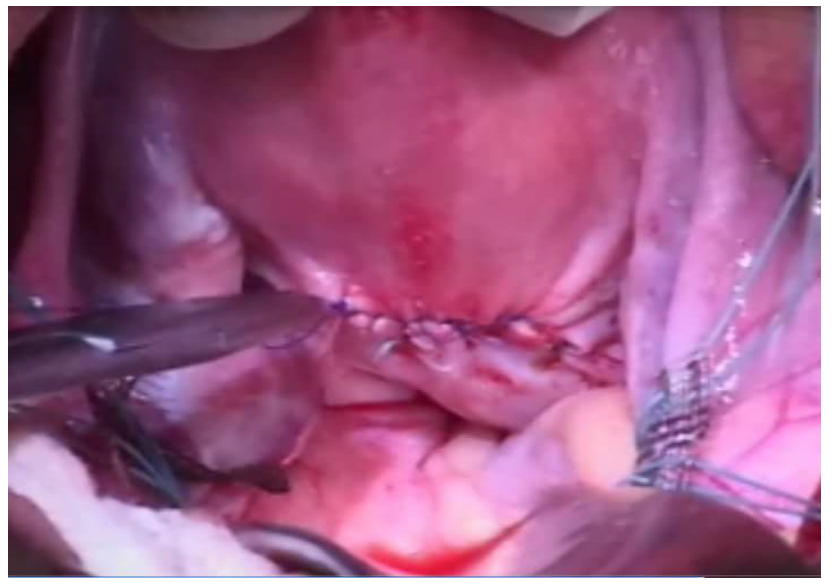

Fig. 4: Reperitonization of all peritoneal opening, so CESA was extraperitoneally

All data preoperative and postoperative, as well as operative details, were collected. All women were reevaluated $6,12,18$ months after hysterosacropexy in the same way as preoperative.

No additional procedures were done at the time of CESA hysteroscacropexy, and any residual prolapse was delayed to be operated after six months on the women request.

The data were statistically described in terms of mean $( \pm \mathrm{SD})$, median (range), number and percentage as appropriate. Comparison of a quantitive variable between the pre and postoperative points was done by paired student t-test, when comparing mean and chi-squared test when comparing percentage, as collected data were normally distributed. $p$-value $<0.05$ were considered statistically significant. Statistical analysis was performed by SPSS version 23 (SPSS Inc, Chicago, IL, USA).

\section{RESULTS}

Twenty women underwent abdominal CESA hysterosacropexy. The demographic characteristics and perioperative criteria were summarized in table 1 . There were no major intraoperative complications or need for blood transfusion. There was no mesh erosion or recurrence of uterine descent throughout the 18 months postoperative follow-up period. There were $2(10 \%)$ cases of mild wound infection and $4(20 \%)$ cases of urinary tract infection which was treated and cured.

Most of twenty women were available for follow up at $6,12,18$ months postoperative follow-up, as we had many contacts to women included in this trial, including home address, mobile and fixed phone's numbers, e-mails address and social media accounts. We considered the result of 6 or 12 months follow up of women who didn't attend the 18 months follow up. 
Objective anatomical improvement was observed from the ICS POP-Q score measurements table 2, apical domain cure rate was $100 \%$ as mean point $C(-7.1)$, mean point D (-8.8), this resulted in apical domain postoperative ICS POPQ stage of 0 or at least stage I and this was maintained in all participants up to 18 months follow up period (this was the primary objective of this trial and it was achieved). Also, this procedure succeeded in a reduction of prolapse in both anterior compartment and posterior compartment and this reductions were statistically significant $(P \leq 0.0001)$ when comparing preoperative ICS POPQ measurement to postoperative ICS POPQ measurement as in table 2. We present functional outcomes in the table 3 . There were statistically significant reductions in prolapse symptoms when the preoperative status was compared to postoperative status including bulge symptoms, OAB, SUI, BD, SD $(P \leq 0.0001, P=0.0064, P=0.03$,
$P=0.008, P \leq 0.0001$ ), respectively. There were another remaining 4 cases with bulge symptoms with residual anterior compartment descent of stage II at six months after abdominal CESA hysterosocropexy. 40\%, 30\%, $35 \%, 70 \%$ of participants with overactive bladder (OAB), stress urinary incontinence (SUI), bowel dysfunction (BD) and sexual dysfunction (SD) respectively were cured of their symptoms after abdominal CESA hysterosacropexy and this cure was maintained in the follow up at $6,12,18$ months.

Objective improvement in prolapse symptoms and bladder function were demonstrated by changes in ICIQ$\mathrm{Vs}(\mathrm{VS}-\mathrm{SS}-\mathrm{QOL})$ score and ICIQ.UI.SF score and this changes between preoperative and postoperative periods were statistically significantly $(P \leq 0.0001)$ in all scores domains as in table 3 .

Table 1: Demographic characteristics and perioperative criteria of women underwent abdominal CESA hysterosacropexy $($ no $=20)$

\begin{tabular}{|c|c|}
\hline Variable & Value \\
\hline Age $(\text { year })^{*}$ & $30.5 \pm 3.2(2.5-36)$ \\
\hline BMI $(\mathrm{kg} / \mathrm{m} 2)^{*}$ & $28.5 \pm 3.5(24-32)$ \\
\hline Parity $(\mathrm{kg} / \mathrm{m} 2)^{*}$ & $2.8 \pm 1.2(2-5)$ \\
\hline $\begin{array}{l}\text { Mode of delivery**: } \\
\text { - Vaginal } \\
\text { - Cesarean section }\end{array}$ & $\begin{array}{c}20(100 \%) \\
0(0 \%)\end{array}$ \\
\hline -Prior vaginal surgery for prolapse** & $8(40 \%)$ \\
\hline -Uterine descent stage on ICS POPQ score** & $8(40 \%)$ \\
\hline Stage II (point $\mathrm{C}, \mathrm{D} \pm 1 \mathrm{~cm}$ from hymen). & $8(40 \%)$ \\
\hline Stage III (point C, D $>1 \mathrm{~cm}<$ TVL-2cm) & $4(20 \%)$ \\
\hline Stage (IV) (Point C, D $\geq$ TVL-2 cm) & \\
\hline Operative TV (min.)* & $98 \pm 14(80-120)$ \\
\hline Hospital stay (hour)* & $54 \pm 13(36-72)$ \\
\hline - Time of first flatus (hour)* & $15 \pm 7.6(6-24)$ \\
\hline
\end{tabular}

Abberivation: BMI: Body Mass index, TVL: Total vaginal length, ICS POPQ: International incontinence society pelvic organ prolapse - Quantification system .

- Data were given as mean \pm standard deviation (range)* or number (percentage)**

- $P<0.05$ : statistically significant 
Table 2: Objective anatomical outcomes of abdominal CESA hysterosacropexy at 18 months: ICS POPQ system (no = 20)

\begin{tabular}{|c|c|c|c|c|c|c|}
\hline & \multicolumn{6}{|c|}{ ICS POP.Q measurement $\mathrm{cm}(\mathrm{n}=20)$} \\
\hline & Aa & $\mathrm{Ba}$ & $\mathrm{C}$ & $\mathrm{D}$ & Ap & $\mathrm{Bp}$ \\
\hline $\begin{array}{l}\text { Preoperative } \\
- \text { Mean } \\
-(\mathrm{SD}) \\
\text {-Median } \\
\text { - (range) }\end{array}$ & $\begin{array}{c}1.5 \\
(1.1) \\
1 \\
(0 \text { to }+3)\end{array}$ & $\begin{array}{c}2.5 \\
(1.8) \\
2 \\
(0 \text { to }+5)\end{array}$ & $\begin{array}{c}2.1 \\
(3.3) \\
6 \\
(-1 \text { to }+9)\end{array}$ & $\begin{array}{c}2.2 \\
(3.1) \\
5 \\
(-1 \text { to }+9)\end{array}$ & $\begin{array}{c}-0.5 \\
(1.9) \\
1 \\
(-1 \text { to }+3)\end{array}$ & $\begin{array}{c}-0.9 \\
(1.8) \\
1 \\
(-2 \text { to }+4)\end{array}$ \\
\hline $\begin{array}{l}\text { Postoperative } \\
- \text { Mean } \\
-(\mathrm{SD}) \\
\text { - Median } \\
\text { - (range) }\end{array}$ & $\begin{array}{c}-1.4 \\
(1.1) \\
-1 \\
(-3 \text { to } 0)\end{array}$ & $\begin{array}{c}-1.9 \\
(1.4) \\
-3 \\
(-4-0)\end{array}$ & $\begin{array}{c}-7.1 \\
(1.1) \\
-7 \\
(-8 \text { to }-6)\end{array}$ & $\begin{array}{c}-8.8 \\
(1.2) \\
-9 \\
(-10 \text { to }-8)\end{array}$ & $\begin{array}{c}-2.5 \\
(1.2) \\
-3 \\
(-3 \text { to }-1)\end{array}$ & $\begin{array}{c}-2.8 \\
(1.3) \\
-4 \\
(-5 \text { to }-2)\end{array}$ \\
\hline $\begin{array}{l}\text { Difference } \\
\text { (post-pre- } \\
\text { operative) mean }\end{array}$ & 2.9 & 4.4 & 9.2 & 11 & 2 & 1.9 \\
\hline P. value & $\leq 0.0001$ & $\leq 0.0001$ & $\leq 0.0001$ & $\leq 0.0001$ & 0.0003 & 0.0005 \\
\hline
\end{tabular}

Abbreviations: ICS POPQ: International incontinence society pelvic organ prolapse-Quantification system.

$P<0.05$ : Statistical significant.

Table 3: Functional outcomes of abdominal CESA hysterosacropexy at 18 months : prolapse symptoms and ICIQ-VS(VS-SS-QOL) score and ICIQ-UI-SF score $($ no $=20)$

\begin{tabular}{|c|c|c|c|c|}
\hline & $\begin{array}{l}\text { Preoperative } \\
\mathrm{No}=20\end{array}$ & $\begin{array}{l}\text { Postoperative } \\
\mathrm{No}=20\end{array}$ & $\begin{array}{l}\text { Difference } \\
\text { (Post -preoperative) }\end{array}$ & $P$ \\
\hline $\begin{array}{l}\text { Prolapse symptoms } \\
\text { no(\%) B.S. }\end{array}$ & $20(100 \%)$ & $4(20 \%)$ & $80 \%$ & $\leq 0.0001$ \\
\hline OAB & $10(50 \%)$ & $2(10 \%)$ & $40 \%$ & 0.0064 \\
\hline SUI & $8(40 \%)$ & $2(10 \%)$ & $30 \%$ & 0.03 \\
\hline $\mathrm{BD}$ & $8(40 \%)$ & $1(5 \%)$ & $35 \%$ & 0.008 \\
\hline $\mathrm{SD}$ & $16(80 \%)$ & $2(10 \%)$ & $70 \%$ & $\leq 0.0001$ \\
\hline $\begin{array}{l}\text { ICIQ VS (VS-SS-QOL) } \\
\text { score VS scale }(0-53)\end{array}$ & $29.5( \pm 5.1)$ & $4.2( \pm 1.8)$ & -25.3 & $\leq 0.0001$ \\
\hline $\begin{array}{l}\text { Mean (SD) } \\
\text { Median (range) }\end{array}$ & $32(16-49)$ & $6(2-10)$ & & \\
\hline $\begin{array}{l}\text { SS scale }(0-56) \\
\text { Mean (SD) } \\
\text { Median (range) }\end{array}$ & $38.8( \pm 5.8)$ & $10.5( \pm 4.4)$ & -28.3 & $\leq 0.0001$ \\
\hline $\begin{array}{l}\text { QOL scale (0-10) } \\
\text { Mean (SD) } \\
\text { Median (range) }\end{array}$ & $8.2( \pm 1.6)$ & $1.8( \pm 0.8)$ & -6.4 & $\leq 0.0001$ \\
\hline $\begin{array}{l}\text { ICIQ-UI.S score }(0-21) \\
\text { Mean (SD) } \\
\text { Median (range) }\end{array}$ & $11.5( \pm 4.1)$ & $2.5( \pm 1.7)$ & -9.0 & $\leq 0.0001$ \\
\hline
\end{tabular}

Abbreviations: BS: Bulge symptoms, OAB: Overactive bladder, SUI: Stress urinary incontinence, BD: Bowel dysfunction, SD: Sexual dysfunction, ICIO-VS(vs-ss-QOL): International consultation incontinence Questionnaire- vaginal symptoms (vaginal symptoms - sexual symptoms - quality of life), ICIO - UI-SF: International consultation incontinence questionnaire urinary incontinence - short form, (SD): standard deviation.

$P<0.05$ : Statistically significant. 


\section{DISCUSSION}

The results of the current study demonstrated that treatment of uterovaginal prolapse of stage II or greater in ICS POPQ system mainly in apical domain in young women aiming in uterine preserving POP surgery by abdominal bilateral USLs augmentation with CESA mesh kit of DynaMesh (abdominal CESA hysterosacropexy) resulted in significant improvement of both anatomical and functional domains of POP sequel. Significant anatomical improvements were recorded in apical, posterior and anterior domains of ICS POP-Q system. Significant functional improvements were noticed from a greater reduction in the percentage of women with prolapse symptoms as BS, OBA, SUI, SD, BD after surgery. Significant objective functional improvements were recorded in the prolapse symptoms, sexual function, quality of life [ICIQ-VS(VS-SS-QOL) score] measures and urinary impact (ICIQ - UI - SF score) measures.

Trials that involved reinforcement of the USLs in correcting apical prolapse either vaginal ${ }^{[19,20]}$ or abdominal ${ }^{[21-24]}$ were few, however, vaginal mesh based hysteropexy was losing favor due to rising incidence of mesh erosions and pelvic pain ${ }^{[4]}$. While trials that utilized CECA/VASA mesh kit of DynaMesh were the prospective trials of Jager et al., Ludwig et $a l$., Joukhadar et al. and the retrospective study of Rajshekhar et al. ${ }^{[9,16,17,18]}$ all these studies reported very high apical anatomical POP cure rates.

Jager et al. firstly described CESA / VASA at 2012, as a procedure for treatment of urge (UUI) and mixed urinary (MUI) incontinence in association with POP. They reported apical anatomical POP cure rate 100\% without recurrence or mesh erosion ${ }^{[9]}$.

Ludwig et al. conducted a trial of CESA/VASA on 71 women with stage I or II ICS POPQ with MUI or UUI and reported apical cure rate of $100 \%$ and great improvement in MUI and UUI ${ }^{[17]}$.

Joukhador et al. reported a trial on CESA / VASA by laparoscopy on 10 cases, their results were similar in apical prolapse cure rate and incontinence symptoms improvement as they reported, apical success rate to be $100 \%$ and remained stable, but with recurrent cystocele in $10 \%$. Also, they reported an improvement of SUI in 5 of 6 patients and cured of $80 \%$ of patient with $\mathrm{OAB}^{[16]}$.

Similar results, as regards apical prolapse domain cure rate and prolapse related symptoms improvement were reported by Rajshekhar et al. on retrospective study utilized CESA/VASA mesh kit to correct POP in 60 older age women doing either CESA with subtotal hysterectomy or VASA on vault prolapse ${ }^{[18]}$.

However, all these trials utilizing CESA/ VASA mesh kit of DynaMesh were done either on vault prolapse (VASA) or associated with subtotal hysterectomy (CESA) and were conducted in elder group of women, and all these trials were without intention for uterine preserving POP surgery.

To the best of our knowledge, this study was the first trial on CESA mesh of DynaMesh as uterine preserving POP surgery, in young women with advanced uterovaginal prolapse with an intention for uterine preserving POP surgery.

Uccella et al., reported a maintained cure of 7 women undergoing laparoscopic uterosacral plication for 17 months follow up ${ }^{[21]}$. Maher et al. described laparoscopic suture hysteropexy in 43 women and reported an objective success rate of $79 \%$ at 12 months ${ }^{[22]}$.

Cutner et al., innovated a laparoscopic technique of uterine suspension bilaterally to the sacral promontory using Mersilene tape to augment uterosacral ligaments. Their first ten women reported 100\% improvement in their symptoms, but $50 \%$ subsequently needed an anterior repair $^{[23,24]}$.

In this trial, there was no intraoperative complication, or blood transfusion as women with suspected pelvic adhesion were excluded, and the choice of S2 to anchor the posterior mesh pieces seems to be safe area in comparison to sacral promontory which is closed to bifurcation of the abdominal aorta and left common iliac vein, or to the S3-S4 level where midsacral plexus of veins exist ${ }^{[25]}$.

No mesh erosions were reported up to date in our cohort of CESA hystrosacropexy. Also, this existed in other CESA/VASA trials ${ }^{[9,16,17,18]}$. This could be explained by very low mesh volume with CESA / VASA up to $10 \%$ of usual mesh used in laparotomic or laparoscopic sacropexy ${ }^{[8,2,26,27]}$ and technique of small peritoneal windows with mesh tunneling, so the entire mesh was totally extraperitoneal, this could also explain non development of mesh-related bowel obstruction that was reported in other traditional abdominal mesh sacropexy ${ }^{[8,12,26,27]}$. Also, visceral dysfunction reported in associations with traditional sacropexy were lessened in CESA/VASA secondary to varying the point of attachment of mesh from the sacral promontory to the $\mathrm{S} 2$ which ensures a more physiological axis of the vagina ${ }^{[9,10,17,18]}$.

There was a difficulty in evaluating any single procedure for prolapse repair due to the procedure 
always combined with other to address another compartment prolapse and/or anti-incontinence procedures. Also, the trials evaluating anti prolapse procedures usually varied in the route of repair, type of mesh, symptoms questionnaire, definition of success and duration of follow up and the existing data were from small cohort trials with very few randomized trials.

The main limitation of the present study was the small sample size and the relatively short duration of follow up.

Recently, Wolfan Jager in 2018 wrote a chapter in hysterectomy textbook, under the title of Uterine prolapse repair without removing the uterus: uterosacropexy and uterorectosacropexy, describing this procedure in details as uterine preserving surgery for pelvic organ prolapse ${ }^{[28]}$.

\section{CONCLUSION}

The results of the present study show that abdominal CESA hysterosacropexy is a safe and effective treatment option for advanced uterovaginal prolapse in women with a desire for uterine preserving POP surgery as it provides excellent uterine support and good functional outcomes with significant overall improvement in sexual function, prolapse symptoms, quality of life and urinary outcomes. An extended period of follow up is needed to confirm these findings over the longer term and detecting any procedurerelated morbidity.

\section{ACKNOWLEDGMENT:}

The authors want to thank their colleges, fellows, patients who helping them in completing this study.

\section{CONFLICT OF INTEREST}

There are no conflict of interest

\section{REFERENCES}

1. Maher CM, Feiner B, Baessler $\mathrm{K}$ and Glazener CMA. "Surgical management of pelvic organ prolapse in women: the updated summary version Cochrane review". Int. Urogynecol J, 2011; 22 (11) : 1445-1457.

2. Summers A, Winkel LA, Hussain HK and Delancey JO. The relationship between anterior and apical compartment support. Am J Obstet Gynecol. 2006; 194 : 1438-1443.

3. Gutman $\mathrm{R}$ and Maher C. Uterine-preserving POP surgery. Int Urogynecol J 2013; 24 : 1803-1813.
4. Skoczylas LC, Turner LC, Wang L, Winger DG and Shepherd JP. Changes in prolapse surgery trends relative to FDA notifications regarding vaginal mesh. Int Urogynecol J, 2013; 25(4): 471-477.

5. Coolen ALWM, van Oudheusden AMJ, van Eijndhoven HWE, Van der Heiiden TPFM, Stokmans RA, Mol BWJ, et al. A comparison of complications between open abdominal sacrocolpopexy and laparoscopic sacrocolpopexy for the treatment of vault prolapse. Obstetrics and Gynecology International, 2013; Article ID 528636, 7 Pages.

6. Higgs PJ, Chua HL and Smith AR. Long term review of laparoscopic sacrocolpopexy. BJOG, 2005; 112 (8): 1134-1138.

7. LeClaire FL, Mukati MS, Juarez D, White D and Quiroz LH. Is de novo stress incontinence after sacrocolpopexy related to anatomical changes and surgical approach?. Int Urogynecol J 2014; 25 (9): 1201-1206.

8. Cosma S, Menato G, Ceccaroni M, Marchino GL, Petruzzelli P, Volpi E, et al. Laparoscopic sacropexy and obstructed defecation syndrome : an anatomo clinical study, Int Urogynecol J, 2013; 24 (10): 1623-1630.

9. Jager W, Mirenaska $\mathrm{O}$ and Brugge S. Surgical treatment of mixed and urge urinary incontinence in women. Gynecol Obstet Invest 2012; 74 (2): 157- 164.

10. Culligan PI, Blackwell L, Goldsmith LJ, Graham CA, Rogers A and Heit MH. A randomized controlled trial comparing fascia lata and synthetic mesh for sacral colpopexy- Obstet Gynecol 2005; 106 (1): 29- 37.

11. Klinge U, Klostethalfen B, Ottinger AP, Junge $\mathrm{K}$ and Schumpelick V. PVDF as a new polymer for the construction of surgical meshes. Biomaterials, 2002; 23 (16): 3487-3493.

12. Nygaard IE, McCreery R, Brubaker L, Connolly A, Cundiff G, Weber AM, et al. Abdominal sacrocolpopexy: a comprehensive review. Obstet Gynecol 2004; 104 (4): 805-823.

13. Bump RC, Mattiasson A, Bo K, Brubaker LP, Delancey JO, Klarskov $\mathrm{P}$, et al. The standardization of terminology of female pelvic organ prolapse and pelvic floor dysfunction. Am J Obstet Gynecol. $1996 ; 175: 10-17$.

14. Price N, Jackson SR, Avery K, Brookes ST and Abrams P. Development and psychometric evaluation of the ICIQ vaginal symptoms questionnaire: ICIQ-VS. BJOG 2006; $113:$ 700-712. 
15. Avery K, Donovan J, Peters TJ, Shaw C, Gotoh $\mathrm{M}$ and Abrams P. ICIQ : A Brief and robust measure for evaluating the symptoms and impact of urinary in continence. Neurourol \& Urodyn, $2004 ; 23: 322-330$.

16. Joukhadar R, Meyberg-Solomayer G, Hamza A, Radosa J, Bader W, Barski D, et al. A novel operative procedure for pelvic organ prolapse utilizing a MRIvisible mesh implant: safety and outcome of modified laparoscopic bilateral sacropexy. Bromed Res Int, $2015: 2015: 860784$.

17. Ludwig S, Stumm M, Mallmann $P$ and Jager W. Surgical replacement of the uterosacral and pubourethral -ligaments as treatment for urgency urinary incontinence. Aust J Wom Health 2016; 3(1): 1019.

18. Rajshekhar S, Mukhopadhyay S and Morris Edword. Early safety and efficacy outcomes of a novel technique of sacrocolpopexy for the treatment of apical prolapse. Int J Gynecol Obstet 2016; http://dx.dol.org/10.1016/J. iJ90.2016.05.007.

19. Ulmsten $U$ and Petros P. Intravaginal slingplasty (IVS): an ambulatory surgical procedure for treatment of female urinary incontinence. Scand J Urol Nephrol 1995; 29 (1): 75-82.

20. Jenkins 2nd VR. Uterosacral ligament fixation for vaginal vault suspension in uterine and vaginal vault prolapse. Am J Obstet Gynecol 1997; 177 (6) : 1337-1343.

21. Uccella S, Ghezzi F, Bergamini V, Serati M, Cromi A, Franchi $\mathrm{M}$, et al. Laparoscopic uterosacral ligaments plication for the treatment of uterine proolapse. Arch Gynecol Obstet 2007; 276 (3): 225-229.
22. Maher CF, Carrey MP and Murray CJ. Laparoscopic suture hysteropexy for uterine prolapse. Obstet Gynecol 2001; 97 (6): 1010-1014.

23. Cutner A, Kearney R and Vashisht A. Laparoscopic uterine sling suspension : a new technique of uterine suspension in women desiring surgical management of uterine prolapse with uterine conservation. BJOG 2007; 114(9) : 1159-1162.

24. Vashisht A, Kearney $\mathrm{R}$ and Cutner A. The new laparoscopic uterine sling suspension procedure : first year follow-up data. Gynecol Surg 2011; 8(3) : 321-323.

25. Good MM,Abele TA, Balgobin S, Montoya TJ, Mcintire D and Corton MM. vascular and ureteral anatomy relative to the midsacral promontory. Am J Obstet Gynecol. 2013; 208 (6): 486. e1-7.

26. Brubaker I, Nygaard I, Richter HE, Visco A, Weber AM, Cundiff GW,

27. Two-year outcomes after sacrocolpopexy with and without burch to prevent stress urinary incontinence. Obstet Gynecol 2008; 112(1) : 49-55.

28. Begley JS, Kupferman SP, Kuznetsov DD, Kobashi $\mathrm{KC}$, Govier FE, MoGonigle KF, et al. Incidence and management of abdominal sacrocolpopexy mesh erosions. Am J Obstet Gynecol. 2005; 192 (6): $1956-62$.

29. Jaeger W. Uterine prolapse repair without removing the uterus: uterosacropexy and uterorectosacropexy. In: Alkaltout I., Mettler L. (eds) Hysterectomy. Springer, Cham 2018, DOlhttps://doi.org/10.1007.978-3-319-22497-8_93. 